\title{
Impedance, Electrical and Dielectric behaviour of Tin Oxide Nanoparticle doped with Graphite, Graphene Oxide and Reduced Graphene Oxide
}

\author{
Benny Sebastian ${ }^{1,2, *}$, C.George Thomas . ${ }^{2}$ and B.Manoj. ${ }^{2}$ \\ ${ }^{1}$ Bharathiar University, Coimbatore, INDIA \\ ${ }^{2}$ Department of Physics and Electronics, CHRIST University, Bengaluru, INDIA \\ *E-mail: benny.sebastian@christuniversity.in
}

doi: $10.20964 / 2021.08 .17$

Received: 29 March 2021 / Accepted: 23 May 2021 / Published: 30 June 2021

\begin{abstract}
Nanostructured materials have attained incredible interest in recent days due to their distinctive chemical, physical, mechanical, magnetic and optoelectronic properties. In the present study, metal nano particle $\left(\mathrm{SnO}_{2}\right)$ was doped with graphite, graphene oxide $(\mathrm{GO})$ and reduced graphene oxide (rGO) with various composition $(1: 100),(1: 1)$ and $(100: 1)$ by weight ratio. The citrate-nitrate gel combustion method was used to prepare nanocrystalline $\mathrm{SnO}_{2}$ while $\mathrm{GO}$ and $\mathrm{rGO}$ were synthesized through modified Hummer's method. The preparation of $\mathrm{SnO}_{2}$-rGO composites was done using a one-step hydrothermal process. The electrical and structural behaviour of the composites of graphite, GO and rGO mixed with $\mathrm{SnO}_{2}$ were elucidated by the impedance analyzer in the frequency range from $10 \mathrm{~Hz}$ to $1 \mathrm{MHz}$. It is observed that the composite of $\mathrm{SnO}_{2}$ with graphite and reduced graphene oxide have similar broad characteristics while $\mathrm{SnO}_{2}$ mixed with $\mathrm{GO}$ is exhibiting different properties which could be attributed to the presence of oxygen functionaries.
\end{abstract}

Keywords: Nanocomposites, Graphene oxide, Reduced graphene oxide, Tin oxide.

\section{FULL TEXT}

(C) 2021 The Authors. Published by ESG (www.electrochemsci.org). This article is an open access article distributed under the terms and conditions of the Creative Commons Attribution license (http://creativecommons.org/licenses/by/4.0/). 